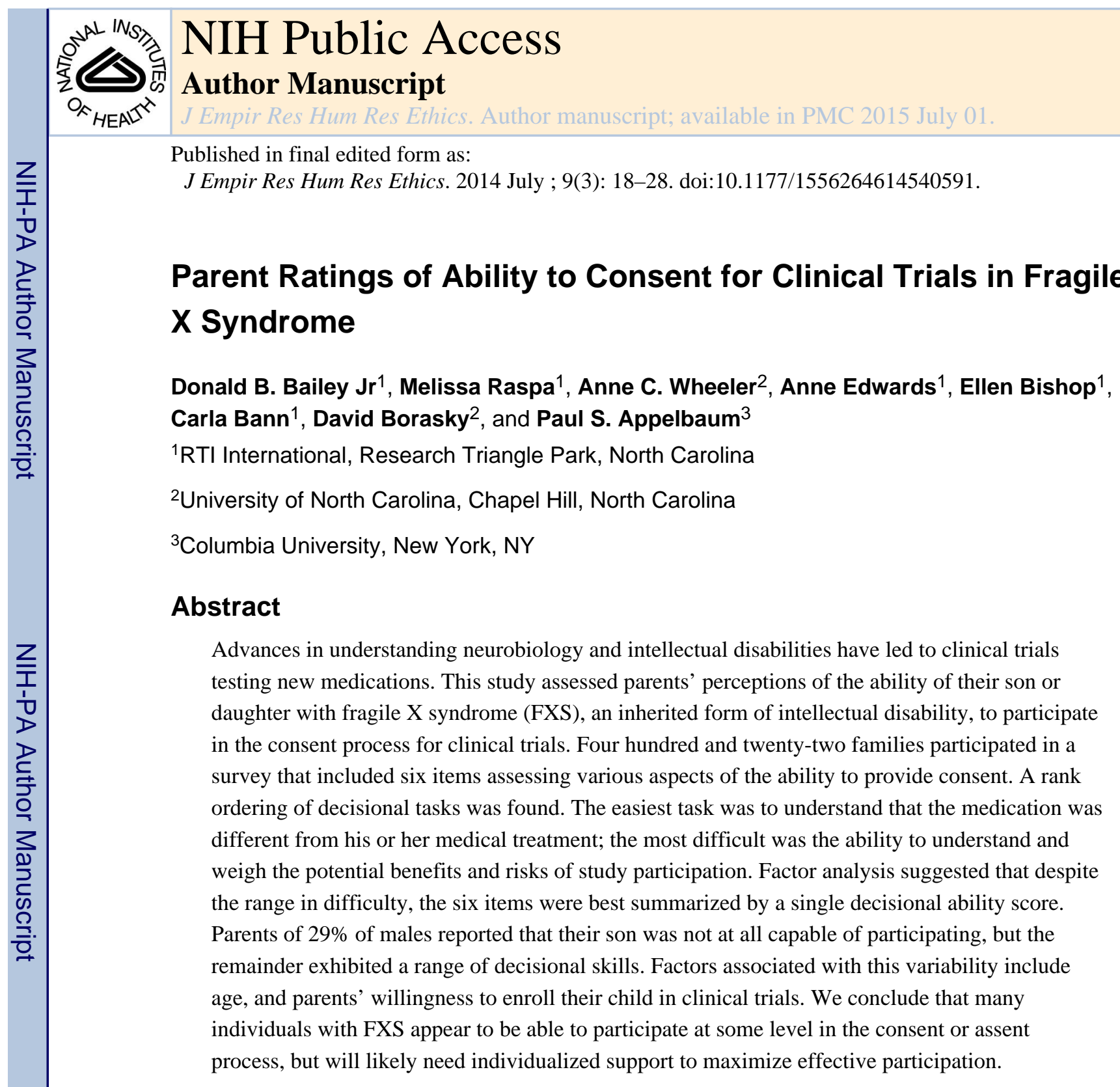

\title{
Keywords
}

informed consent; clinical trials; fragile X syndrome; decisional capacity

\begin{abstract}
Any study with human subjects must have a robust consent process to ensure that participants understand the study and can determine involvement. But investigators studying individuals with intellectual and developmental disabilities (IDD) face a special challenge (Becker, Roberts, Morrison, \& Silver, 2004; Feudtner \& Brosco, 2011). They must determine whether an individual can make an informed decision and the supports needed to maximize participation in decision making. Fulfilling this obligation requires appreciation of the human rights context of research (Iacono \& Carling-Jenkins, 2012), knowledge of the
\end{abstract}

Corresponding author: Don Bailey, Ph.D., RTI International, 3040 Cornwallis Rd., Research Triangle Park, NC, 27709, USA, dbailey@rti.org, (919-541-6488). 
person's disability and skills, and evidence-based adaptations to maximize informed decision making (Calveley, 2012; Williams \& Moore, 2011).

These issues are important in all human studies, but clinical trials testing new treatments may warrant additional scrutiny. Clinical trials are necessary to assure safe and effective interventions, but their application to IDD evokes complex considerations (Robotham, King, Canagasabey, Inchley-Mort, \& Hassiotis, 2011; Welie \& Berghmans, 2006). For bot reasons of science (the need to demonstrate efficacy in the population for whom a treatment is intended) and distributive justice (the need to assure that vulnerable individuals have equal access to potentially beneficial treatments), the participation of individuals with IDD in research is important (Yan \& Munir, 2004). But some will get a placebo, the medication may have side effects, blood draws may be needed, and assessments are needed to assess efficacy and safety. Researchers want to maximize enrollment to ensure a successful study. Parents, hoping to help their child or contribute to new knowledge, may encourage their son or daughter to participate—even if some study requirements are uncomfortable or demanding. These factors suggest that individuals with IDD should be more actively involved in the consent or assent process, but little is known about the extent to which they can understand the study, what is expected, and potential risks or benefits.

We have initiated a longitudinal study of decisional capacity and informed consent in fragile $\mathrm{X}$ syndrome (FXS), the most common inherited form of IDD. As a prelude to our direct assessment protocol, we report here a brief survey assessing parent perceptions of their son or daughter's ability to participate in the consent process.

\section{Consent and IDD}

By definition, individuals with IDD have cognitive impairments limiting ability to make informed choices. Historically, individuals with IDD played virtually no role in life decisions (Noll \& Trent, 2004). Prevailing views gradually changed throughout the last half of the 20th century, as disability rights advocates, parents, and ethicists began calling for respect of autonomy and empowerment of individuals with IDD, invoking principles such as self-advocacy, self-determination, and normalization (Powers, Dinerstein, \& Holmes, 2005).

Although the Common Rule requires protections for pregnant women, prisoners, and children, individuals with IDD are relegated to a generic "vulnerable populations" status needing additional protections. The regulations require legally effective informed consent from participants or their legally authorized representative (LAR). But what constitutes "legally effective" is left to the jurisdiction in which the research is conducted. Although several groups have called for greater specificity and direction in legislation (e.g., National Bioethics Advisory Committee, 1998), none have been forthcoming in the U.S.

Parents, LARs, and researchers would benefit from education and data supporting effective strategies for enhancing participation in the consent process, but unfortunately, the empirical literature is limited (Cleaver, Ouellette-Kuntz, \& Sakar, 2010; Goldsmith, Skirton, \& Webb, 2008). Several studies have described challenges in research recruitment (Evenhuis et al., 2004; Lennox et al., 2005), but no studies have documented decision-making skills in individuals with IDD as a group or in specific subgroups. Most authors acknowledge the 
wide range of ability. Although a robust consent requirement cannot be waived for vulnerable individuals assume that many individuals with IDD could participate in the consent process at some level (Goldsmith et al., 2008; Veenstra et al., 2010).

Several factors associated with decisional capacity have been identified, the most obvious of which is cognitive ability. But cognition consists of multiple processes including attention, memory, executive function, strategy use, and metacognitive processing (Bebko \& Luhaorg, 1998). Virtually nothing is known about their relative contribution to decisional capacity.

Other related factors include the complexity and presentation of information, the relationship between study participants and researchers, caregiver participation, and prior experiences in decision making (Cea \& Fisher, 2003; Fisher, Cea, Davidson, \& Fried, 2006; Goldsmith et al., 2008).

\section{Fragile X Syndrome (FXS)}

FXS, an inherited disorder resulting in cognitive impairment and other functional limitations, exemplifies these challenges. Males typically have moderate intellectual disability, but impairment can range from mild to severe; females are more mildly affected, ranging from normal cognition to moderate impairment (Hall, Burns, Lightbody, \& Reiss, 2008; Loesch, Huggins, \& Hagerman, 2004). FXS is highly associated with a range of cooccurring conditions, such as attention and behavior problems, anxiety, and autism (Bailey, Raspa, Olmsted, \& Holiday, 2008).

Recent advances in understanding the molecular basis of FXS have led to a new generation of targeted medications (Gross, Berry-Kravis, \& Bassell, 2012; Wijetunge, Chattarji, Wyllie, \& Kind, 2013), with increasing interest in their potential for individuals with autism spectrum disorders (ASD) (Baudouin et al., 2012). Shared pathways in the biology of neurodevelopmental disabilities suggest that treatments targeting these pathways could benefit individuals with diverse causes of IDD (Lipton \& Sahin, 2013; Millan, 2013). As a result, there has been a significant increase in clinical trials testing medications that target critical points in neural pathways (Berry-Kravis et al., 2012; Gross et al., 2012; Jacquemont et al., 2011).

To maximize participation in consent for these trials, research is needed to characterize profiles of decisional capacity in specific groups of individuals with IDD. Studies of FXS have shown particular deficits in sustained attention, response inhibition, working memory, and other executive functions associated with decisional capacity (Baker et al., 2011; Hooper et al., 2008; Ornstein et al., 2008; Sullivan et al., 2007). Reading is a challenge for males (Roberts et al., 2005); a national survey reported that although $44 \%$ of adult males with FXS could read basic picture books or simple stories, only $19 \%$ could read books that contain new words or concepts (Bailey, Raspa, Holiday, Bishop, \& Olmsted, 2009). In contrast, $91 \%$ of adult females could read basic picture books or simple stories, and $76 \%$ could read books that contain new words. 


\section{Purpose}

To provide an initial assessment of the extent to which individuals with FXS could participate in the consent process, we included a module on decisional capacity in a parent survey. The study was designed to answer three questions:

Question 1. How do parents rate the extent to which their son or daughter with FXS is able to make a decision about study participation? We assessed parent perceptions of whether their son or daughter would understand six specific tasks in the consent process. We hypothesized that we would find a range of abilities, but wanted to know the distribution across each, determine the proportion that parents consider not capable on any dimensions of decisional capacity, and ascertain whether parents considered some fully capable of participating in all aspects of consent.

Question 2. Are there identifiable components of decision-making, and are some tasks more difficult than others? We conducted exploratory analyses to determine whether the six items would result in a single factor, and then tested the assumption that items requiring more complex understanding would be significantly more difficult than more concrete tasks.

Question 3. What factors are associated with variability in parent ratings? We hypothesized that males and younger individuals with FXS would be rated as having lower decisional capacity than females or older individuals with FXS. We also tested whether respondent (parent) gender, education, and interest in clinical trial participation were associated with ratings of decisional capacity.

\section{METHODS}

\section{Participants}

The study was part of a national survey of families affected by FXS. Participants were recruited from a registry of more than 1000 families of children with FX; announcements were also posted on the web sites of the National Fragile X Foundation (www.nfxf.org) and FRAXA Research Foundation (www.fraxa.org). A total of 730 families completed the entire survey. Of those, 422 had a son or daughter with FXS $\geq 12$ years of age. Although children $<18$ years are not legally able to consent, we were interested in earlier indications of decisional capacity and thus included younger children in the study.

One parent completed the survey on behalf of the family. Most respondents were white (93\%), others were Hispanic (2\%), African American (2\%), or other races/ethnicities (3\%). Thirty-eight percent had a 2-year college degree or less education, 34\% a 4-year degree, and $28 \%$ a graduate or professional degree. Approximately one-quarter had an annual family income of $\$ 50,000$ or less $(24.5 \%), 36.4 \% \$ 50,001-\$ 100,000$, and $39 \%>\$ 100,000$. Most were mothers (90\%), married (81\%), and employed (65\%). Their mean age was 53.1 years (10.3 SD). They had an average of 1.6 children ( $0.8 \mathrm{SD})$, and reported on atotal of 505 children with FXS ages 12 and older. Age ranges of the children were $12-17$ years (31\%), $18-22$ years (22\%), $23-29$ years (22\%), and $\geq 30$ (25\%). Most children were males (89\%). 


\section{Informed consent}

Survey items were reviewed by the Institutional Review Board at the first author's home institution. Because we asked parents provided information about their adult son or daughter, the IRB had to consider whether we could ask parents these questions without their son or daughter's consent. The IRB agreed that most males with FXS would be considered "decisionally impaired" and thus allowed parent report. However, because females are more mildly affected, the IRB determined that we could only ask parents about their adult daughter if they were the legal guardian of that child. Given that we had only a total of 58 females in the study and the adult females were more severely involved individuals who needed a legal guardian, we limit our report on females to a brief summary.

\section{Procedures}

Respondents completed the survey online (94\%) or by telephone (6\%). Parents were given a brief study description, assured that it was voluntary and confidential, and asked to read a consent form and acknowledge that they agreed to survey participation.

\section{Decisional capacity}

Respondents completed items about their son or daughter's participation in clinical trials and their ability to consent. Willingness to have their child participate in future clinical trials was also ascertained $(1=$ definitely, $2=$ probably, $3=$ not sure, $4=$ probably not , and $5=$ definitely not). Respondents were then presented the following scenario: Assume that [CHILD] is asked to be in a research study to see whether a new medication is effective. The study will last for 6 weeks. During that time, [he/she] will either get the new medicine or a sugar pill. [CHILD] will have blood drawn every week, and every other day [he/she] will be asked a set of questions about how [he/she] is feeling. The medicine might improve some things and might have some mild side effects, such as sleep problems. If this study was explained to [CHILD] in relatively simple terms, please rate the extent to which you think [he/she] would be able to do the following. Respondents then rated ability to understand that (a) he/she is being asked to participate in a study to find out if a medication works for people with FXS; (b) the study medication is different from regular treatment; (c) he/she might get the medication or a sugar pill; (d) there are both potential benefits and risks of participating; and (e) he/she can choose to participate and to withdraw at any time. Respondents also rated ability to make a decision about study participation. Each item was rated on a 4-point scale $(0=$ not at all capable $; 1=$ capable but with a lot of support $; 2=$ capable with only minimal support; 3 = fully capable). The scenario and items were adapted from the MacArthur Competence Assessment Tool for Clinical Research (MacCAT-CR) (Appelbaum \& Grisso, 2001), in collaboration with the scale's primary author.

\section{Data Analysis}

We calculated percentages to provide item-level descriptive data. To account for missing data, percentages are based on the number of respondents for each question. To examine characteristics associated with variation in decisional abilities, we calculated a total abilityto-consent score, summing the six items (range 0-18). Items were rank-ordered by difficulty, and paired t-test procedures with a Bonferroni correction for multiple 
comparisons were used to compare adjacent items. We conducted a multiple regression analysis using child age, respondent education, respondent gender, and parents' willingness to participate in clinical trials as predictors.

\section{RESULTS}

\section{Views about Clinical Trials}

Parents generally were positive about clinical trials. When asked if they would be willing for their son or daughter to participate in one, a majority responded definitely $(28.8 \%)$ or probably (29.4\%). Some were unsure (27.4\%), and only a few responded probably not $(11.9 \%)$ or definitely not $(2.6 \%)$.

\section{Parent Ratings of Decisional Tasks}

Parent ratings of males and females by each decisional task are displayed in Table 1. For males, ratings of "not at all capable" ranged from $34.2 \%$ to $63.3 \%$ across items; for females these ratings ranged from $10.3 \%$ to $24.1 \%$. The group of males was then sub-divided by age ( $<18$ years or $\geq 18$ years), displayed in Table 2 , to examine differences in abilities before and after the typical age of consent. As expected, parents rated lower decisional abilities for sons under age 18 than those 18 or over (see Table 2). For males under 18 years, ratings of "not at all capable" ranged from $48.9 \%$ to $76.7 \%$, whereas for males $\geq 18$ years, ratings of "not at all capable" ranged from $29.6 \%$ to $57.6 \%$.

When examining all items simultaneously, 29\% of males were rated as "not at all capable" on all six items, in comparison with only $7 \%$ of females. From another perspective, $32 \%$ of males and $74 \%$ of females had no items rated as "not at all capable," suggesting a wide range of ability and the potential for participation with support. However, for males, ratings of "fully capable" ranged from only $2.9 \%$ to $15.5 \%$ across items; for females these ratings ranged from $29.3 \%$ to $48.3 \%$. Only $2.2 \%$ of males were rated as "fully capable" on all six items, in comparison with $25.9 \%$ of females.

\section{Item Clustering and Difficulty Level}

Using a scoring system from 0 (not at all capable) to 3 (fully capable), we calculated means and standard deviations for each item, displayed in Table 3 for males, in order from least to most difficult. The tasks receiving the highest ratings (reflecting least difficulty) were "understands that this medication is different from his/her regular treatment" and "realizes that he/she can choose to participate in the study or withdraw at any time." The tasks receiving the lowest ratings (reflecting the greatest difficulty) were "can make a decision about study participation" and "understands and weighs the potential benefits and risks of participating in the study." We ran paired t-tests to compare mean scores on each of the adjacent pairs of items. The comparisons between all adjacent items were significant after a Bonferroni correction except for two pairs of items: (1) "understands being asked to participate" and "can choose to participate or withdraw at any time," and (2) "understands that he/she might get the medication and/or he/she might get a sugar pill" and "make a decision about study participation," providing a clear rank order of difficulty. 
We then calculated a total decisional ability score by summing the item ratings, resulting in a score ranging from 0 (not at all capable on all six items) to 18 (fully capable on all six items). The distribution of total decisional ability scores for males and females is displayed in Figure 1. The distributions are both skewed, but in the opposite direction, reflecting the expected differences in cognitive ability between males and females. To determine the validity of a single score, we first computed item-total correlations (i.e., the correlation between the item and the total score with the item removed) and factor loadings based on a 1 -factor exploratory factor analysis. The item-total correlations were all high, ranging from 0.86 to 0.90 , and the factor loadings ranged from 0.90 to 0.93 . Cronbach's alpha for the scale was very high, 0.96 . Together these findings suggest that the six items are best summarized by a single decisional ability score.

\section{Factors Associated with Decisional Ability}

To examine the extent to which variability in decisional ability was associated with selected child or family characteristics, we conducted a multiple regression analysis using child age, respondent education, respondent gender, and willingness to participate in clinical trials as predictors of the total decisional ability score (Table 4). Because of the small number of females, the regression analysis was restricted to males. Parent willingness to have their child participate in a clinical trial and child age were significantly $(\mathrm{p}<.01)$ associated with decisional ability. Parents interested in clinical trials were more likely to rate their son higher in decisional ability. Age was also a significant predictor, as evidenced by the item level ratings in Table 2. The mean total score for males under age 18 was 3.47 ( $\mathrm{SD}=4.2$ ); whereas for males $\geq 18$ years the mean was $5.80(\mathrm{SD}=5.4)$. The full distribution of total scores for males as a function of age is displayed in Figure 2. Although the regression line shows a positive association with age, the figure demonstrates the high degree of variability both within and across age groups.

\section{DISCUSSION}

Translational research in IDD is leading to new treatments targeting core disease mechanisms rather than presenting symptoms (Wang et al., 2013). This research has led to a rapid increase in clinical trials to test the efficacy of new medications. Ethical imperatives suggest that individuals with IDD ought to have a say in whether they will enroll in clinical trials, but empirical data on their decisional skills is lacking. Researchers, parents, and IRB members need data and assessment tools so that modifications in the consent process can be made to support and maximize participation in decision making in either consent or assent to participate. Unfortunately the literature is scant, and to the best of our knowledge, there are no published reports of decisional abilities in specific groups of individuals with IDD.

This study is an initial attempt to fill this void by assessing parents' perspectives on the decisional abilities in FXS. Because a hallmark feature of FXS is cognitive impairment, limitations in decisional ability were expected. However, variability in cognitive development and the prevalence of co-occurring conditions (Bailey et al., 2008) suggest that a range of functioning is possible. We also wanted to determine if some tasks were more 
difficult than others. Finally, we wanted to identify characteristics associated with variability in decisional skills.

Parents of $29 \%$ of males reported that their son was "not at all capable" of participating in any of the six decisional tasks included in our survey. But the remaining parents reported that their son could participate in at least some of these tasks, although virtually all of them would need significant support to do so. The six tasks were not of equal difficulty, and the two rated as most challenging - weighing benefits and risks and making a decision about study participation-are central to the consent process and indeed reflect the ultimate goal of informed consent. As expected, males were substantially less able to participate in the consent process than females and adult males had more decisional skills than adolescents.

Parent education was not associated with ratings of decisional ability, but parents who were more interested in having their son or daughter participate in a clinical trial rated their children as having more decisional skills than parents who were less certain about or opposed to clinical trial participation. Although one reason for this finding might be a tendency for parents who want their children to participate in research to attribute higher levels of decisional abilities to them, the causal arrow could point in the opposite direction. Parents who perceive their children as functioning at a higher level, and thus better able to participate in decision-making, may be more willing to see them enter clinical trials. We are not able to distinguish between these possibilities based on our data, and further exploration of this question might help to better illuminate the nature of parental perspectives on research participation.

Several limitations must be acknowledged. First, the findings are based on only one parent's report of decisional ability, the validity of which is unknown especially if some carrier parents have mild impairments in executive function (Kraan et al., 2013). Some parents may never have had to consider their child's ability to consent and may not have fully grasped the tasks described. Alternatively, having cared for and observed their children over many years, they probably had a strong sense of abilities and limitations. The usefulness of these findings will be enhanced by direct assessments of decisional skills and factors associated with decisional capacity, and by further examination of other parent characteristics potentially associated with variability in ratings. Second, the findings are primarily limited to males, as the female sample was much smaller and the adult females studied are not representative of the broader population of adult females with FXS. Finally, the survey sample is primarily White and all live in the U.S. Cross-cultural and international contexts almost certainly play important roles in shaping both perceptions of disability and policies regarding consent and approaches to research (Roberts, Petticrew, Liabo, \& Macintyre, 2012), and further investigation of these issues in other contexts is essential.

\section{BEST PRACTICES}

Early research on strategies to enhance participation in consent focused on simplifying language and modifying the presentation (Bjorn, Rossel, \& Holm, 1999; Dresden \& Levitt, 2001; Murphy, O'Keefe, \& Kaufman, 1999). Multimedia formats (slides, videos, touchscreens) have been tested (Agre et al., 2003; Dunn et al., 2002), as well as test-teach 
paradigms (Stiles, Poythress, Hall, Falkenbach, \& Williams, 2001; Wirshing, Wirshing, Marder, Liberman, \& Mintz, 1998). But most of these studies have not focused on individuals with IDD. Goldsmith, Skirton, and Webb (2008) reviewed studies of interventions for individuals with ID and found that life experiences-residence, history of decision making, previous health experiences - contributed to the ability to consent (Arscott, Dagnan, \& Kroese, 1999; Cea \& Fisher, 2003; Dye, Hare, \& Hendy, 2007; Fisher et al., 2006). Also, method of presentation is important, especially for individuals with poor communication skills or lower memory ability (Dunn et al., 2006; Wong, Clare, Holland, Watson, \& Gunn, 2000). Many studies show that general intelligence, verbal ability, and memory are correlated with ability to consent (Arscott et al., 1999; Cea \& Fisher, 2003; Dye et al., 2007; Fisher et al., 2006; Wong et al., 2000).

\section{Research Agenda}

These findings should be validated using objective assessments, and systematic studies of parent perceptions and parent agreement on decisional abilities are needed. Factors associated with the capacity to consent, such as executive functions, need to be assessed (Mandarelli, Parmigiani, Tarsitani, et al., 2013). We still do not have a validated approach to enhance decisional capacity in individuals with IDD (Cleaver et al., 2010). A variety of techniques may be needed depending on the participant's skills (Swaine et al., 2011). New technologies, primarily applications designed for tablets such as the iPad, have great potential for enhancing communication with people with IDD (Kagohara et al., 2013; Palmer, Wehmeyer, Davies, \& Stock, 2012; Shane et al., 2012).

\section{Educational Implications}

Our findings suggest that most males with FXS will have significant challenges participating in the consent process. However, given the variability in decisional abilities, researchers should develop strategies to maximize participation and assent or consent. It is likely than no single approach will work for all individuals with IDD, necessitating individualized assessments, evidence-based supports, and a model that maximizes the goodness-of-fit between an individual's abilities and the consent process (Calveley, 2012; Fisher, 2003).

\section{Acknowledgments}

This project was funded in part by a grant from the Centers for Disease Control and Prevention, National Center on Birth Defects and Developmental Disabilities under Cooperative Agreement U01DD000231 to the Association of University Centers on Disabilities (RTOI 2010-999-0), and in part by the Eunice Kennedy Shriver National Institute for Child Health and Human Development (R01HD071987). The content of this material does not necessarily reflect the views and policies of CDC, NCBDDD, AUCD or NICHD. The authors express their grateful appreciation to the hundreds of parents who took the time to participate in this survey.

\section{Biographies}

Don Bailey is a Distinguished Fellow at RTI International. His research focuses on individuals with FXS, family adaptation to disability, and newborn screening. He is Principal Investigator of the NIH project that provided partial support for this work. He conceived of the project and is the primary author of this paper. 
Melissa Raspa is Research Analyst at RTI International. Her research focuses on children with disabilities and outcomes for families of children with disabilities. She was involved in the design of this project, data analysis, data interpretation and writing/reviewing the manuscript.

Anne Wheeler is a Clinical Scientist at the Center for Intellectual and Developmental Disabilities, University of North Carolina at Chapel Hill. Her research focuses on family adaptation to disability and the clinical assessment of children with disabilities. She was Principal Investigator of the CDC project that supported the survey reported in this paper, and was involved in the design, analysis and interpretation of findings and writing/reviewing the manuscript.

Ellen Bishop is a Research Statistician at RTI International, focusing on statistical analysis of health research on children and families. She managed all of the data for the survey project, conducted many of the statistical analyses, and was involved in writing the data portions of the manuscript.

Carla Bann is a Fellow of statistics and psychometrics at RTI International. She specializes in complex data analyses and modeling procedures, and her research focuses on quality of life. She provided statistical guidance for this project, conducted the factor analyses reported, and wrote sections of the manuscript reporting those analyses.

David Borasky is Deputy Director, Office of Human Research Ethics, University of North Carolina at Chapel Hill. He provided guidance on developing the consent protocol for the project and wrote sections of the introduction related to the history of involving vulnerable populations in research.

Paul Appelbaum is a Professor in the Department of Psychiatry at Columbia University. His research focuses on ethical issues in the consent process, and he is author of the MacArthur Competence Assessment Tool for Clinical Research. This scale served as the basis for developing survey questions and he reviewed and provided input on manuscript drafts.

\section{References}

Agre P, Campbell FA, Goldman BD, Boccia ML, Kass N, McCullough LB, Wirshing D. Improving informed consent: The medium is not the message. IRB; A Review of Human Subjects Research, Suppl. 2003; 25(5):S11-S19.

Appelbaum, PS.; Grisso, T. MacArthur competence assessment tool for clinical research. Sarasota, FL: Professional Resource Press; 2001.

Arscott K, Dagnan D, Kroese BS. Assessing the ability of people with a learning disability to give informed consent to treatment. Psychological Medicine. 1999; 29(6):1367-1375. [PubMed: 10616942]

Bailey DB Jr, Raspa M, Olmsted M, Holiday DB. Co-occurring conditions associated with FMR1 gene variations: Findings from a national parent survey. American Journal of Medical Genetics Part A. 2008; 146A(16):2060-2069. [PubMed: 18570292] 
Bailey DB, Raspa M, Holiday D, Bishop E, Olmsted M. Functional skills of individuals with fragile X syndrome: A lifespan cross-sectional analysis. American Journal on Intellectual and Developmental Disabilities. 2009; 114(4):289-303. [PubMed: 19642710]

Baker S, Hooper S, Skinner M, Hatton D, Schaaf J, Ornstein P, Bailey D. Working memory subsystems and task complexity in young boys with Fragile X syndrome. Journal of Intellectual Disability Research. 2011; 55(1):19-29. [PubMed: 21121991]

Baudouin SJ, Gaudias J, Gerharz S, Hatstatt L, Zhou K, Punnakkal P, Scheiffele P. Shared synaptic pathophysiology in syndromic and nonsyndromic rodent models of autism. Science. 2012; 338(6103):128-132. [PubMed: 22983708]

Bebko, JM.; Luhaorg, H. The development of strategy use and metacognitive processing in mental retardation: Some sources of difficulty. In: Burack, JA.; Hodapp, RM.; Zigler, E., editors. Handbook of mental retardation and development. Cambridge, UK: Cambridge University Press; 1998. p. 382-410.

Becker H, Roberts G, Morrison J, Silver J. Recruiting people with disabilities as research participants: Challenges and strategies to address them. Mental Retardation and Developmental Disabilities Research Reviews. 2004; 42:471-475.

Berry-Kravis EM, Hessl D, Rathmell B, Zarevics P, Cherubini M, Walton-Bowen K, Hagerman RJ. Effects of STX209 (arbaclofen) on neurobehavioral function in children and adults with fragile X syndrome: a randomized, controlled, phase 2 trial. Science Translational Medicine. 2012; 4(152): 152 ra127.

Bjorn E, Rossel P, Holm S. Can the written information to research subjects be improved?-An empirical study. Journal of Medical Ethics. 1999; 25(3):263-267. [PubMed: 10390684]

Calveley J. Including adults with intellectual disabilities who lack capacity to consent in research. Nursing Ethics. 2012; 19(4):558-567. [PubMed: 22753458]

Cea CD, Fisher CB. Health care decision-making by adults with mental retardation. Mental Retardation. 2003; 41(2):78-87. [PubMed: 12622524]

Cleaver S, Ouellette-Kuntz H, Sakar A. Participation in intellectual disability research: A review of 20 years of studies. Journal of Intellectual Disability Research. 2010; 54(3):187-193. [PubMed: 20146739]

Dresden GM, Levitt MA. Modifying a standard industry clinical trial consent form improves patient information retention as part of the informed consent process. Academic Emergency Medicine. 2001; 8(3):246-252. [PubMed: 11229946]

Dunn LB, Lindamer LA, Palmer BW, Golshan S, Schneiderman LJ, Jeste DV. Improving understanding of research consent in middle-aged and elderly patients with psychotic disorders. American Journal of Geriatric Psychiatry. 2002; 10(2):142-150. [PubMed: 11925275]

Dye L, Hare DJ, Hendy S. Capacity of people with intellectual disabilities to consent to take part in a research study. Journal of Applied Research in Intellectual Disabilities. 2007; 20:168-174.

Evenhuis H, van Splunder J, Vink M, Weerdenburg C, van Zanten B, Stilma J. Obstacles in large-scale epidemiological assessment of sensory impairments in a Dutch population with intellectual disabilities. Journal of Intellectual Disability Research. 2004; 48(Pt 8):708-718. [PubMed: 15494060]

Feudtner C, Brosco JP. Do people with intellectual disability require special human subjects research protections? The interplay of history, ethics, and policy. Developmental Disabilities Research Reviews. 2011; 17(1):52-56. [PubMed: 22447756]

Fisher CB. Goodness-of-fit ethic for informed consent to research involving adults with mental retardation and developmental disabilities. Mental Retardation and Developmental Disabilities Research Reviews. 2003; 9(1):27-31. [PubMed: 12587135]

Fisher CB, Cea CD, Davidson PW, Fried AL. Capacity of persons with mental retardation to consent to participate in randomized clinical trials. American Journal of Psychiatry. 2006; 163(10):18131820. [PubMed: 17012694]

Goldsmith L, Skirton H, Webb C. Informed consent to healthcare interventions in people with learning disabilities_An integrative review. Journal of Advanced Nursing. 2008; 64(6):549-563. [PubMed: 19120568] 
Gross C, Berry-Kravis EM, Bassell GJ. Therapeutic strategies in fragile X syndrome: Dysregulated mGluR signaling and beyond. Neuropsychopharmacology. 2012; 37(1):178-195. [PubMed: 21796106]

Hall SS, Burns DD, Lightbody AA, Reiss AL. Longitudinal changes in intellectual development in children with Fragile X syndrome. Journal of Abnormal Child Psychology. 2008; 36(6):927-939. [PubMed: 18347972]

Hooper SR, Hatton D, Sideris J, Sullivan K, Hammer J, Schaaf J, Bailey DP Jr. Executive functions in young males with fragile $\mathrm{X}$ syndrome in comparison to mental age-matched controls: Baseline findings from a longitudinal study. Neuropsychology. 2008; 22(1):36-47. [PubMed: 18211154]

Iacono T, Carling-Jenkins R. The human rights context for ethical requirements for involving people with intellectual disability in medical research. Journal of Intellectual Disability Research. 2012; 56(11):1122-1132. [PubMed: 23106755]

Jacquemont S, Curie A, des Portes V, Torrioli MG, Berry-Kravis E, Hagerman RJ, Gomez-Mancilla B. Epigenetic modification of the FMR1 gene in fragile $\mathrm{X}$ syndrome is associated with differential response to the mGluR5 antagonist AFQ056. Science Translational Medicine. 2011; 3(64):64ra61.

Kagohara DM, van der Meer L, Ramdoss S, O'Reilly MF, Lancioni GE, Davis TN. Using iPods and iPads in teaching programs for individuals with developmental disabilities: A systematic review. Research in Developmental Disabilities. 2013; 34:147-156. [PubMed: 22940168]

Kraan CM, Hocking DR, Bradshaw JL, Fielding J, Cohen J, Georgiou-Karistianis N, Cornish KM. Neurobehavioural evidence for the involvement of the FMR1 gene in female carriers of fragile $\mathrm{X}$ syndrome. Neuroscience and Biobehavioral Reviews. 2013; 37(3):522-547. [PubMed: 23352653]

Lennox N, Taylor M, Rey-Conde T, Bain C, Purdie DM, Boyle F. Beating the barriers: Recruitment of people with intellectual disability to participate in research. Journal of Intellectual Disability Research. 2005; 49(Pt 4):296-305. [PubMed: 15816817]

Lipton J, Sahin M. Fragile X syndrome therapeutics: Translation, meet translational medicine. Neuron. 2013; 77:212-213. [PubMed: 23352156]

Loesch DZ, Huggins RM, Hagerman RJ. Phenotypic variation and FMRP levels in fragile X. Mental Retardation and Developmental Disabilities Research Reviews. 2004; 10(1):31-41. [PubMed: 14994286]

Mandarelli G, Parmigiani G, Tarsitani L, Frati P, Biondi M, Ferracuti S. The relationship between executive functions and capacity to consent to teatment in acute psychiatric hospitalization. Journal of Emprical Research on Human Research Ethics. 2013; 7:63-70.

Millan MJ. An epigenetic framework for neurodevelopmental disorders: From pathogenesis to potential therapy. Neuropharmacology. 2013; 68:2-82. [PubMed: 23246909]

Murphy DA, O'Keefe ZH, Kaufman AH. Improving comprehension and recall of information for an HIV vaccine trial among women at risk for HIV: Reading level simplification and inclusion of pictures to illustrate key concepts. AIDS Education and Prevention. 1999; 11(5):389-399. [PubMed: 10555623]

National Bioethics Advisory Committee. Research involving persons with mental disorders that may affect decision-making capacity. Vol. Vol. I. Rockville, MD: National Bioethics Advisory Committee; 1998.

Noll, S.; Trent, JW. Mental retardation in America: A historical reader. New York, NY: University Press; 2004.

Ornstein PA, Schaaf JM, Hooper SR, Hatton DD, Mirrett P, Bailey DB Jr. Memory skills of boys with fragile X syndrome. American Journal of Mental Retardation. 2008; 113(6):453-465. [PubMed: 19127656]

Palmer SB, Wehmeyer ML, Davies DK, Stock SE. Family members' reports of the technology use of family members with intellectual and developmental disabilities. Journal of Intellectual Disability Research. 2012; 56(4):402-414. [PubMed: 21988242]

Powers, L.; Dinerstein, R.; Holmes, S. Self-advocacy, self-determination, and social freedom and opportunity. In: Lakin, KC.; Turnbull, A., editors. National goals and research for people with intellectual and developmental disabilities. Washington, DC: American Association on Mental Retardation; 2005. 
Roberts H, Petticrew M, Liabo K, Macintyre S. The Anglo-Saxon disease: A pilot stud of the barriers to and facilitators of the use of randomized controlled trials of social programmes in an international context. Journal of Epidemiology and Community Health. 2012; 66:1025-1029. [PubMed: 22412153]

Roberts JE, Schaaf JM, Skinner M, Wheeler A, Hooper S, Hatton DD, Bailey DB Jr. Academic skills of boys with fragile X syndrome: Profiles and predictors. American Journal of Mental Retardation. 2005; 110(2):107-120. [PubMed: 15762821]

Robotham D, King M, Canagasabey A, Inchley-Mort S, Hassiotis A. Social validity of randomized control trials in health services research and intellectual disabilities: A qualitative exploration of stakeholder views. Trials. 2011; 12:144. [PubMed: 21658215]

Shane HC, Laubscher EH, Schlosser RW, Flynn S, Sorce JF, Abramson J. Applying technology to visually support language and communication in individuals with autism spectrum disorders. Journal of Autism and Developmental Disorders. 2012; 42(6):1228-1235. [PubMed: 21691867]

Stiles PG, Poythress NG, Hall A, Falkenbach D, Williams R. Improving understanding of research consent disclosures among persons with mental illness. Psychiatric Services. 2001; 52(6):780-785. [PubMed: 11376225]

Sullivan K, Hatton DD, Hammer J, Sideris J, Hooper S, Ornstein PA, Bailey DB Jr. Sustained attention and response inhibition in boys with fragile $\mathrm{X}$ syndrome: Measures of continuous performance. American Journal of Medical Genetics Part B: Neuropsychiatric Genetics. 2007; 144B(4):517-532.

Swaine J, Parish SL, Luken K, Atkins L. Recruitment and consent of women with intellectual disabilities in a randomised control trial of a health promotion intervention. Journal of Intellectual Disability Research. 2011; 55(5):474-483. [PubMed: 21385259]

The Belmont Report. Ethical principles and guidelines for the protection of human subjects of research. Washington, DC: DHHS; 1978.

Veenstra MY, Walsh PN, van Schrojenstein Lantman-de Valk HM, Haveman MJ, Linehan C, Kerr MP, Moravec D. Sampling and ethical issues in a multicenter study on health of people with intellectual disabilities. Journal of Clinical Epidemiology. 2010; 63(10):1091-1100. [PubMed: 20304607]

Wang X, Zhao Y, Zhang X, Badie H, Zhou Y, Mu Y, Xu H. Loss of sorting nexin 27 contributes to excitatory synaptic dysfunction by modulating glutamate receptor recycling in Down's syndrome. Nature Medicine. 2013; 19(4):473-480.

Welie SP, Berghmans RL. Inclusion of patients with severe mental illness in clinical trials: issues and recommendations surrounding informed consent. CNS Drugs. 2006; 20(1):67-83. [PubMed: 16396525]

Wijetunge LS, Chattarji S, Wyllie DJ, Kind PC. Fragile X syndrome: From targets to treatments. Neuropharmacology. 2013; 68:83-96. [PubMed: 23257237]

Williams AS, Moore SM. Universal design of research: Inclusion of persons with disabilities in mainstream biomedical studies. Science Translational Medicine. 2011; 3(82):82cm12.

Wirshing DA, Wirshing WC, Marder SR, Liberman RP, Mintz J. Informed consent: Assessment of comprehension. American Journal of Psychiatry. 1998; 155(11):1508-1511. [PubMed: 9812110]

Wong JG, Clare CH, Holland AJ, Watson PC, Gunn M. The capacity of people with a 'mental disability' to make a health care decision. Psychological Medicine. 2000; 30(2):295-306. [PubMed: 10824650]

Yan EG, Munir KM. Regulatory and ethical preinciples in research involving children and individuals with developmental disabilities. Ethics and Behavior. 2004; 14(1):31-49. [PubMed: 15580725] 


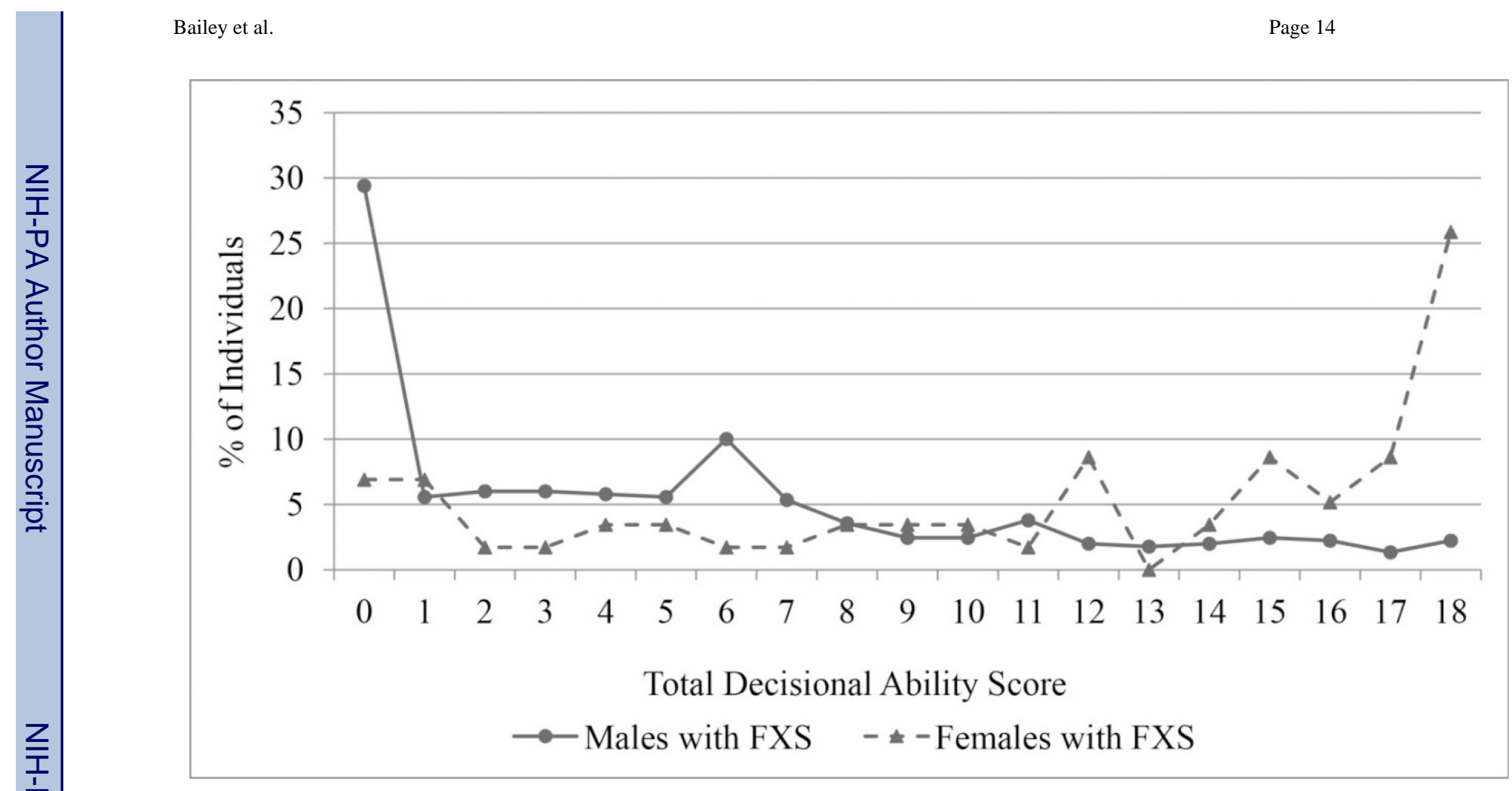

Figure 1.

Total decisional ability score for males and females with FXS

J Empir Res Hum Res Ethics. Author manuscript; available in PMC 2015 July 01. 


\section{Decisional Capacity Score by Age}

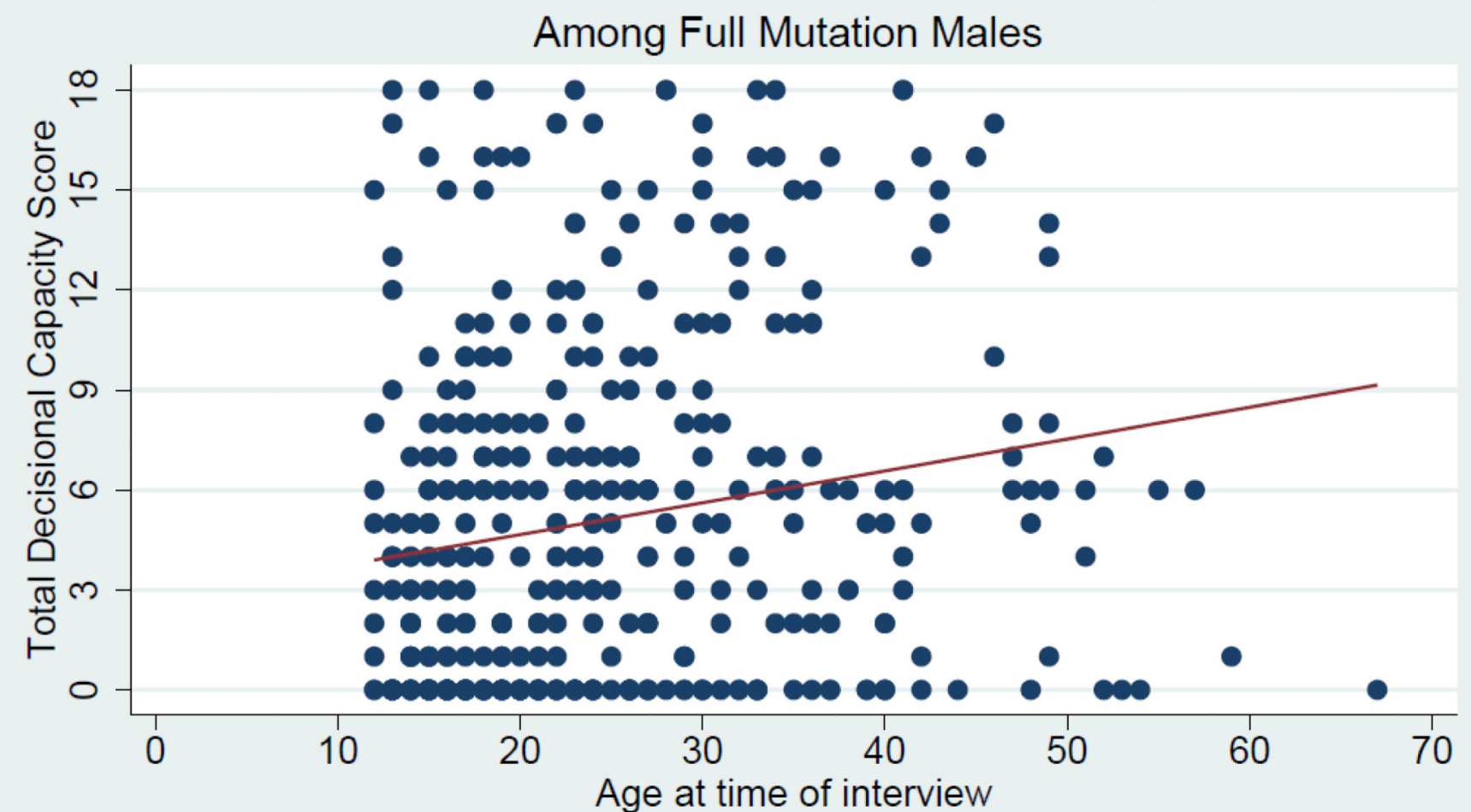

Age at time of interview

\section{- decisional capacity score - Fitted values}

Source: Phase2 Fragile X National Survey, CDC

Figure 2.

Parent ratings of decisional capacity in males with fragile $\mathrm{X}$ syndrome as a function of age of child. 


\section{Table 1}

Parent ratings of decisional abilities for males and females with FXS as a function of decisional task

\begin{tabular}{|c|c|c|}
\hline Decisional Task & $\begin{array}{r}\text { Percentage of } \\
\text { Males } \\
(n=447)\end{array}$ & $\begin{array}{l}\text { Percentage of } \\
\text { Females } \\
(\mathbf{n}=\mathbf{5 8})\end{array}$ \\
\hline \multicolumn{3}{|c|}{ Understand being asked to participate in study } \\
\hline Not at all capable & 38.1 & 13.8 \\
\hline Capable but with a lot of support & 37.0 & 19.0 \\
\hline Capable with only minimal support & 15.0 & 19.0 \\
\hline Fully capable & 9.9 & 48.3 \\
\hline \multicolumn{3}{|c|}{ Understand that study medication differs from regular } \\
\hline Not at all capable & 34.2 & 10.3 \\
\hline Capable but with a lot of support & 32.4 & 20.7 \\
\hline Capable with only minimal support & 17.8 & 20.7 \\
\hline Fully capable & 15.5 & 48.3 \\
\hline \multicolumn{3}{|c|}{ Understand might get medication or sugar pill } \\
\hline Not at all capable & 51.9 & 15.5 \\
\hline Capable but with a lot of support & 26.0 & 17.2 \\
\hline Capable with only minimal support & 13.8 & 19.0 \\
\hline Fully capable & 8.3 & 48.3 \\
\hline \multicolumn{3}{|c|}{ Understand and weigh potential benefits and risks } \\
\hline Not at all capable & 63.3 & 24.1 \\
\hline Capable but with a lot of support & 25.0 & 15.5 \\
\hline Capable with only minimal support & 8.8 & 31.0 \\
\hline Fully capable & 2.9 & 29.3 \\
\hline \multicolumn{3}{|c|}{ Realize choice and ability to withdraw at any time } \\
\hline Not at all capable & 42.4 & 17.2 \\
\hline Capable but with a lot of support & 29.6 & 12.1 \\
\hline Capable with only minimal support & 15.8 & 22.4 \\
\hline Fully capable & 12.2 & 48.3 \\
\hline \multicolumn{3}{|c|}{ Able to make a decision about study participation } \\
\hline Not at all capable & 51.0 & 22.4 \\
\hline Capable but with a lot of support & 31.2 & 13.8 \\
\hline Capable with only minimal support & 9.9 & 24.1 \\
\hline Fully capable & 7.9 & 39.7 \\
\hline
\end{tabular}

Note: Percentages may not sum to 100 due to rounding. 
Table 2

Parent ratings of decisional abilities for males with FXS as a function of decisional task and age

\begin{tabular}{|c|c|c|}
\hline Decisional Task & $\begin{array}{r}\text { Percentage of } \\
\text { Males <18 yrs. } \\
\quad(n=133)\end{array}$ & $\begin{array}{l}\text { Percentage of } \\
\text { Males } 18 \text { or over } \\
\quad(n=313)\end{array}$ \\
\hline \multicolumn{3}{|c|}{ Understand being asked to participate in study } \\
\hline Not at all capable & 48.9 & 33.6 \\
\hline Capable but with a lot of support & 34.6 & 38.0 \\
\hline Capable with only minimal support & 12.0 & 16.3 \\
\hline Fully capable & 4.5 & 12.1 \\
\hline \multicolumn{3}{|c|}{ Understand that study medication differs from regular } \\
\hline Not at all capable & 45.1 & 29.6 \\
\hline Capable but with a lot of support & 33.1 & 32.2 \\
\hline Capable with only minimal support & 12.0 & 20.3 \\
\hline Fully capable & 9.8 & 18.0 \\
\hline \multicolumn{3}{|c|}{ Understand might get medication or sugar pill } \\
\hline Not at all capable & 64.7 & 46.5 \\
\hline Capable but with a lot of support & 24.8 & 26.5 \\
\hline Capable with only minimal support & 7.5 & 16.5 \\
\hline Fully capable & 3.0 & 10.7 \\
\hline \multicolumn{3}{|c|}{ Understand and weigh potential benefits and risks } \\
\hline Not at all capable & 76.7 & 57.6 \\
\hline Capable but with a lot of support & 18.1 & 28.0 \\
\hline Capable with only minimal support & 3.8 & 10.9 \\
\hline Fully capable & 1.5 & 3.5 \\
\hline \multicolumn{3}{|c|}{ Realize choice and ability to withdraw at any time } \\
\hline Not at all capable & 56.1 & 36.7 \\
\hline Capable but with a lot of support & 28.0 & 30.2 \\
\hline Capable with only minimal support & 11.4 & 17.7 \\
\hline Fully capable & 4.6 & 15.4 \\
\hline \multicolumn{3}{|c|}{ Able to make a decision about study participation } \\
\hline Not at all capable & 66.2 & 44.6 \\
\hline Capable but with a lot of support & 27.1 & 33.0 \\
\hline Capable with only minimal support & 2.3 & 13.1 \\
\hline Fully capable & 4.5 & 9.3 \\
\hline
\end{tabular}

Note: Percentages may not sum to 100 due to rounding. 
Table 3

Mean ratings and order of difficulty for decisional tasks for males with fragile $\mathrm{X}$ syndrome (in increasing order of difficulty).

\begin{tabular}{llr}
\hline Rank & Item Description & Mean (SD) \\
\hline 1 & Understand that this medication is different from his/her regular treatment & $1.26(1.10)$ \\
2 (tied) & Realize that he/she can choose to participate in the study or withdraw at any time & $1.10(1.10)$ \\
2 (tied) & $\begin{array}{l}\text { Understand that he/she is being asked to participate in a research study to find out if the medication works for people } \\
\text { with FXS. }\end{array}$ & $1.09(1.04)$ \\
3 (tied) & Understand that he/she might get the medication or he/she might get a sugar pill & $0.93(1.07)$ \\
3 (tied) & Make a decision about study participation & $0.87(1.02)$ \\
4 & Understand and weigh the potential benefits and risks of participating in the study & $0.65(0.90)$ \\
\hline
\end{tabular}

Note: All pairwise comparisons are significant at $\mathrm{p}<.05$ with Bonferroni correction for multiple comparisons except for the two pairs of items that were essentially identical in rank. 


\section{Table 4}

Regression model predicting total decisional ability score for Males as a function of willingness to participate in a clinical trial; respondent education; and child age

\begin{tabular}{lrrc}
\hline Predictor / Control Variable & Coefficient & $\begin{array}{c}\text { 95\% Confidence } \\
\text { Interval }\end{array}$ & $\begin{array}{c}\text { p- } \\
\text { value }\end{array}$ \\
\hline Willingness to have child participate in clinical trial & & & $<\mathbf{0 . 0 1}$ \\
Definitely & 2.99 & $(-0.30-6.28)$ & 0.08 \\
Probably & 1.87 & $(-1.37-5.11)$ & 0.26 \\
Not sure & .85 & $(-2.37-4.07)$ & 0.60 \\
Probably not & .84 & $(-2.57-4.25)$ & 0.63 \\
Definitely not & REF & & $\cdot$ \\
Respondent education & & & $\mathbf{0 . 3 9}$ \\
Some college or less & -0.85 & $(-2.14-0.43)$ & 0.19 \\
Two or four-year college degree & -0.68 & $(-1.86-0.51)$ & 0.26 \\
Graduate or professional degree & REF & & $\cdot$ \\
Respondent gender & & & $\mathbf{0 . 3 4}$ \\
Male & .72 & $(-.76-2.20)$ & 0.34 \\
Female & REF & & \\
Age of child & & & $\mathbf{0 . 0 1}$ \\
Age 12-17 & & & $<0.01$ \\
Age 18-22 & -3.44 & $(-4.72-2.15)$ & $<0.01$ \\
Age 23-29 & -2.32 & $(-3.72-0.91)$ & 0.01 \\
Age 30 and over & -1.38 & $(-2.76-0.01)$ & 0 \\
\hline
\end{tabular}

Note: $\mathrm{REF}=$ reference category 